\title{
THE VITAL CAPACITY OF THE LUNGS OF CHILDREN
}

A PRELIMINARY REPORT *

\author{
CHESTER A. STEWART, M.D., PH.D. \\ Assistant Professor of Pediatrics, University of Minnesota \\ MINNEAPOLIS, MINN \\ AND \\ O. B. SHEETS, M.D. \\ HOLIYHOOI, CAIIF.
}

It is now definitely recognized that disease of the lungs or of the heart may produce a considerable reduction in the vital capacity of the lungs. Due to the fact that the normal lung capacity, particularly for children, is not generally known, clinicians have experienced difficulty in estimating accurately the extent of the reduction in vital capacity existing in individual cases. As a result such determinations are rarely included in the routine examination of children suffering from alleged cardiac or pulmonary disease.

Rather extensive series of observations made on healthy children have been published especially by Gilbert, ${ }^{1}$ Smedley, ${ }^{2}$ Baldwin, ${ }^{3}$ Emerson and Green ${ }^{4}$ and Wilson and Edwards." Unfortunately, most of these data have appeared in journals not readily accessible to the medical profession. We wish to contribute vital capacity averages for 430 healthy children ( 228 boys, 202 girls), ranging in age from 4 to 15 years inclusive. In addition, observations are reported for five children having bronchiectasis, and for five with tuberculosis.

The vital capacities were measured by means of an accurately calibrated wet spirometer. The children were instructed to take the deepest possible inspiration, and then to empty the lungs completely into the spirometer. Fach child was given several trials, and the maximum amount repeatedly expired was recorded as the vital capacity.

* Received for publication, Jan. 26, 1922.

1. Gilbert, J. A.: Researches on the Mental and Physical Development of School Children; Studies from Yale Psychological Laboratory, 1894, 2: p. 4). Researches on School Children and College Students, University of Iowa Studies in Psychology, 1897, 1: p. 1.

2. Smedley, F. W.: Report of Commissioner of Elucation, 1:1095, 1902.

3. Baldwin, B. T.: Physical Growth and School Progress, U. S. Bureau of Education Bull. No. 10, 1914, p. 6.

4. Emerson, P. W., and Green, H.: Vital Capacity of the Lungs of Children. Am. J. Dis. Child. 22:202 (Aug.) 1921.

5. Wilson, M. G., and Edwards, D. J.: Vital Capacity of the Lungs and Its Relation to Exercise Tolerance in Children with Heart Disease. Standards for Normal Vital Capacity for Children. The Lung Capacity in Certain Intrathoracic Conditions, Am. J. Dis. Child. 22:443 (Nov.) 1921. 
When the cooperation of the child was unsatisfactory the observations were discarded. Care also was taken to include no child suffering either from acute respiratory infections, or from chronic heart or lung disease.

The children were weighed naked, and at the same time the standing height was recorded. The sitting height was measured with the child seated on a chair against a perpendicular scale.

The vital capacity of the lungs for the boys (Table 1) shows an increase with advancing age, from an average of 792 c.c. at 4 years to 3,044 c.c. at 15 years, a gain of 2,252 c.c. For the girls, during a

Table 1.-Agr, Number of Normal Boys and Girls, Average Vital. Capacity (Sexes Separaten)

\begin{tabular}{ccccc}
\hline \hline Age, Years & Number of Boys & $\begin{array}{c}\text { Vital Capacity } \\
\text { Boys, C.c. }\end{array}$ & $\begin{array}{c}\text { Vital Capacity } \\
\text { Girls, C.c. }\end{array}$ & Number of Girls \\
4 & 6 & 792 & 644 & 9 \\
5 & 15 & 936 & 819 & 12 \\
6 & 19 & 1,161 & 1,055 & 26 \\
7 & 27 & 1,320 & 1,214 & 18 \\
8 & 32 & 3,480 & 1,337 & 19 \\
9 & 37 & 1,740 & 1,511 & 23 \\
10 & 14 & 1,828 & 1,740 & 19 \\
11 & 24 & 1,954 & 1,782 & 24 \\
12 & 16 & 2,309 & 2,061 & 8 \\
14 & 18 & 2,383 & 2,288 & 8 \\
\hline
\end{tabular}

Table 2.-Weight, Number of Normal Boys and Giris axi Vitai. Capacity (Sexfis SkparatriJ)

\begin{tabular}{|c|c|c|c|c|}
\hline Weight, Kg. & Number of Boys & $\begin{array}{c}\text { Vital Capacity } \\
\text { Boys, C.c. }\end{array}$ & $\begin{array}{l}\text { Vital Capacity } \\
\text { Girls, C.c. }\end{array}$ & Number of Girls \\
\hline $10-15$ & 3 & 978 & 693 & 7 \\
\hline 20 & 45 & $1,0 \pi 1$ & 975 & (1) \\
\hline 25 & 66 & 1,438 & 1,366 & 39 \\
\hline 30 & 38 & $1,78 j$ & 1,653 & 31 \\
\hline 35 & 29 & $2,0: 8$ & 1,911 & 33 \\
\hline 40 & 24 & 2,323 & 2,081 & 13 \\
\hline 45 & 11 & 0,509 & 2,377 & 11 \\
\hline 50 & 6 & 2,800 & 2,533 & 6 \\
\hline 55 & 5 & 3,108 & 2,713 & 4 \\
\hline
\end{tabular}

similar period the averages increase from 644 c.c. to 2,381 c.c. Thus for the latter the growth in lung capacity amounting to 1,737 c.c. is considerably less than that accomplished by the former $(2,252$ c.c. $)$. The data also show the vital capacity to be constantly lower for girls than for boys at corresponding ages.

In Tables 2, 3 and 4 the data are averaged (sexes separated) according to body weight (in $\mathrm{kg}$.), standing height (in $\mathrm{cm}$.) and sitting height (in $\mathrm{cm}$.), respectively. At this time we will call attention merely to the fact that at either corresponding weight, standing height, or sitting height, the average vital capacity is constantly greater for the 
boys than for the girls. The actual averages for the different body measurements recorded may be obtained by reference to the proper table.

In addition to presenting data for normal children, we are also able to report vital capacity records for five children having bronchiectasis (Table 5). These children were examined by one of us, while working at the Mayo Clinic. The diagnosis in each instance was confirmed by roentgen-ray examination of the lungs. The children gave histories of repeated attacks of bronchitis extending over a long period, and at

Table 3.-Standing Height, Number of Normal Boys and Girls and Average Vital Capacity (Sfixes Sf.parated)

\begin{tabular}{|c|c|c|c|c|}
\hline $\begin{array}{c}\text { Standing } \\
\text { Hejght, Cm. }\end{array}$ & Number of Boys & $\begin{array}{c}\text { Vital Capacity } \\
\text { Boys, C.c. }\end{array}$ & $\begin{array}{l}\text { Vital Capacity } \\
\text { Girls, C.c. }\end{array}$ & Number of Girls \\
\hline $95-100$ & $\overline{3}$ & 732 & 695 & 5 \\
\hline $10 \overline{3}$ & 5 & 850 & 742 & 9 \\
\hline 110 & 12 & 967 & 902 & 17 \\
\hline 115 & 19 & 1,163 & 1,082 & 21 \\
\hline 120 & 25 & 1,323 & 1,182 & 10 \\
\hline 125 & 27 & 1,442 & 1,302 & 20 \\
\hline 330 & 33 & 1,638 & 1,495 & 16 \\
\hline 135 & 24 & 1,790 & 1,730 & 14 \\
\hline 140 & 20 & 1,984 & 1,835 & 23 \\
\hline 143 & ]ั̃ & 2,227 & 1,926 & 2.5 \\
\hline 100 & 8 & 2,413 & 2,175 & 10 \\
\hline 155 & 16 & 2,510 & 2,348 & 11 \\
\hline 160 & 13 & 2,842 & 2,5277 & 35 \\
\hline 16.5 & 7 & 3,210 & 2,812 & 3 \\
\hline
\end{tabular}

Table 4.-Sitring Height, Number of Normal Boys and Girls and Vital. Capacity (Sexpes Siparated)

\begin{tabular}{|c|c|c|c|c|}
\hline $\begin{array}{l}\text { Sitting } \\
\text { Height, Cm. }\end{array}$ & Number of Boys & $\begin{array}{c}\text { Vital Capacity } \\
\text { Boys, C.e. }\end{array}$ & $\begin{array}{l}\text { Vital Capacity } \\
\text { Girls, C.e. }\end{array}$ & Number of Girls \\
\hline $55-57.5$ & 13 & 855 & 812 & 13 \\
\hline 60.0 & 18 & 1,074 & 1,020 & 26 \\
\hline $62 . \overline{5}$ & 23 & 1,250 & 1,149 & 17 \\
\hline 65.0 & 39 & $\mathbf{1}, 408$ & 1,367 & 26 \\
\hline 6it 5 & 37 & 1,624 & 1,589 & 21 \\
\hline 70.0 & 37 & $\begin{array}{l}1,024 \\
1,909\end{array}$ & 1,823 & 28 \\
\hline 72.5 & 19 & $\begin{array}{l}1,470 \\
2,127\end{array}$ & 1,881 & 21 \\
\hline$\because 50$ & 17 & 2,347 & 2,075 & 14 \\
\hline it. & 15 & 2,033 & 2.406 & 17 \\
\hline 80.0 & 7 & 2,900 & $2,5,57$ & 7 \\
\hline
\end{tabular}

the time seen complained of frequent colds, chronic cough, abundant sputum and were in general poor health. With Subjects 1 and 2 (Table 5) definite clubbing of the terminal phalanges of the fingers and toes was noted. Physical examination in each instance revealed the presence of numerous coarse râles particularly at the bases of the lungs.

The data (Table 5) show the existence of a considerable reduction in vital capacity for the first four patients, which is especially pronounced (46 per cent.) for Subject 2. Subject 4 was examined on a second occasion, and her vital capacity again registered 750 c.c. 
This time she was instructed to endeavor to free the bronchi of accumulated secretion by postural cough with the head hanging downward. and at a lower level than that of the chest. After expectorating a considerable amount of sputum in this manner, the vital capacity was again recorded, and was found to have increased from 750 to 1,150 c.c. For Subject 5 the vital capacity actually exceeded the normal average, expected for corresponding age. This girl, however, had been freeing the lungs of excessive secretion by means of postural cough for several weeks, which possibly was a factor in enabling her to register a vital capacity equal to the normal.

Although five cases is too small a number to justify any sweeping statements, nevertheless, it appears safe to conclude that bronchiectasis usually produces a definite reduction in the vital capacity of the lungs, which may be very marked in severe cases. In certain instances, how-

Table 5.-Age in Years, Standing Height in Cm., Weight in Kg., Vital

Capacity in C.C., and Normal Vital Capacity for Corresponding Agr: for Five: Childoren Having Bronchifctasis

\begin{tabular}{|c|c|c|c|c|c|}
\hline $\begin{array}{l}\text { Case } \\
\text { Number } \\
\text { Boys: }\end{array}$ & $\begin{array}{l}\text { Age, } \\
\text { Years }\end{array}$ & $\begin{array}{c}\text { Standing } \\
\text { Height, Cm. }\end{array}$ & $\begin{array}{l}\text { Weight, } \\
\text { Kg. }\end{array}$ & $\begin{array}{c}\text { Vital } \\
\text { Capacity, C.c. }\end{array}$ & $\begin{array}{l}\text { Normal Vital } \\
\text { Capacity for } \\
\text { Corresponding Age, } \\
\text { C.c. }\end{array}$ \\
\hline 1 & 8 & $12 \gamma$ & 21.4 & 1,000 & 1,480 \\
\hline Gris. & $1 \overline{3}$ & 168 & 41.0 & 1,375 & 3,044 \\
\hline $\begin{array}{l}3 \\
4 \\
5\end{array}$ & $\begin{array}{r}6 \\
7 \\
1.2\end{array}$ & $\begin{array}{l}120 \\
1 \geq 1 \\
147\end{array}$ & $\begin{array}{l}24.1 \\
18.0 \\
30.5\end{array}$ & $\begin{array}{r}800 \\
700 \\
2,200\end{array}$ & $\begin{array}{l}1,055 \\
1,214 \\
2,061\end{array}$ \\
\hline
\end{tabular}

ever, the vital capacity may be practically normal in spite of the presence of definite chronic disease of the lungs. A normal vital capacity consequently does not necessarily indicate that the lungs are in a perfectly normal condition.

The vital capacity measurements for five children having tuberculosis are recorded in Table 6. For the two boys the vital capacity of the lungs is extremely subnornal. The first boy has an advanced and active tuberculosis of the lumbar spine complicated by a large psoas abscess. The roentgenograms of the lungs revealed diffuse mottling and fibrosis throughout both lung fields. About six months later a second determination was made, and the vital capacity showed a decrease from 1,050 to 775 c.c. The hospital records revealed that this boy had failed gradually in strength during this period, and was in a much poorer general condition than when first examined.

The second boy's vital capacity is also greatly reduced. He has a healed Pott's disease of the thoracic vertebrae, with extensive ankylosis and a marked kyphosis. Numerous scars of healed sinuses are present along the spine. The roentgen-ray revealed a chronic fibroid condition 
in the lungs. In spite of the enormous reduction in vital capacity, this boy was able to undergo considerable activity with comparatively little dyspnea.

The vital capacity for the first one of the three girls reported is practically normal for her age. She had an active tuberculosis of the hip with many discharging sinuses. The roentgen-ray revealed normal lung fields, and only moderate enlargement and calcification of the glands at the root of the lungs.

The second girl has an advanced and active pulmonary tuberculosis with many areas of consolidation in each lung. Numerous räles are present on both sides, and examination of the sputum revealed many tubercle bacilli. As might be expected, the vital capacity of the lungs of this patient was greatly reduced.

Table 6.-Age, Standing Height, Wigight, Vital Capacity, Normal Vital

Capacity for Corresponding Age, Location and Extent of

Disease for Five: Chimerfon Haling Tubrerculosts

\begin{tabular}{|c|c|c|c|c|c|c|}
\hline $\begin{array}{l}\text { Case } \\
\text { Number }\end{array}$ & $\begin{array}{l}\text { Age, } \\
\text { Years }\end{array}$ & $\begin{array}{l}\text { Standing } \\
\text { Height, } \\
\text { Cm. }\end{array}$ & $\begin{array}{l}\text { Weight, } \\
\text { Kg. }\end{array}$ & $\begin{array}{c}\text { Vital } \\
\text { Capacity, } \\
\text { C.c. }\end{array}$ & $\begin{array}{l}\text { Normal } \\
\text { Vital Capacity } \\
\text { for Corre- } \\
\text { sponding Age }\end{array}$ & $\begin{array}{l}\text { Location } \\
\text { and Fxtent of } \\
\text { T'uberculosis }\end{array}$ \\
\hline $\begin{array}{r}\text { Boys: } \\
1\end{array}$ & 13 & 142 & 21.8 & $1,0 \overline{0} 0$ & $\begin{array}{l}\text { C.c. } \\
2,383\end{array}$ & Lumbar spine; psoas \\
\hline 2 & 15 & 131 & 23.2 & 750 & 3,044 & $\begin{array}{l}\text { Thoracic spine: mark } \\
\text { ed hyphosis: chronic } \\
\text { fbroid: pulmonary } \\
\text { tuberculosis }\end{array}$ \\
\hline Girls: & 11 & 138 & 29.0 & 1,600 & 1,782 & Hip: many sinuses; \\
\hline 4 & $1 \overline{1}$ & 151 & 50.1 & $9 \overline{50}$ & 2,681 & $\begin{array}{l}\text { Advanced pulmonary } \\
\text { tubereulosis }\end{array}$ \\
\hline$i$ & 13 & $14 f i$ & 25.1 & $5 \pi$ & 2,288 & $\begin{array}{l}\text { Advanced pulmonary } \\
\text { with cavities }\end{array}$ \\
\hline
\end{tabular}

The third girl has an advanced pulmonary tuberculosis with cavities present in each lung. At the time the record was made the girl was up and about, and practically free from dyspnea on mild exertion, in spite of the fact that her vital capacity was only slightly more than one third the normal expected for corresponding age. The observation recorded was obtained about three months previous to the death of the patient.

These cases illustrate the extreme reduction in the vital capacity of the lungs which may result from pulmonary tuberculosis. Undoubtedly, these patients at one time had a normal vital capacity, but following the development of a tuberculous infection, the vital capacity apparently progressively decreased as the pathologic process advanced. Repeated determinations made during this period probably would have given striking and unmistakable evidence through the progressive diminution in vital capacity, that the pathologic condition present in the lungs was gradually increasing. While single measurements of 
the vital capacity are no doubt of value in detecting the presence of pulmonary diseases, repeated determinations are vastly more valuable, for changes in the pathologic process present are promptly reflected by fluctuations in the vital capacity of the lungs. Therefore, the progress of the disease may be followed by noting the effect on the vital capacity. Instead of relying on indefinite clinical notes or memory regarding the presence of abnormal breath sounds, or extent of areas of dulness, etc., recorded on previous examinations, an accurate measurement in cubic centimeters of the vital capacity of the lungs can be established from which except for the normal increase accompanying growth there should be very little constant deviation on subsequent examinations. The occurrence of any permanent reduction in the vital capacity below previous determinations apparently will give immediate clue to the development or extension of pathologic processes within the chest.

\section{SUMMARY}

1. The averages for the vital capacity of the lungs of 430 healthy children ( 228 boys; 202 girls), grouped according to age, weight, standing height and sitting height, are recorded. The averages show the vital capacity of the lungs to be constantly greater for the boys than for the girls of corresponding age and size.

2. Vital capacity records are reported for five children having bronchiectosis and also for five children suffering from tuberculosis, which demonstrate the marked reduction in vital capacity which these conditions may produce. 